\title{
Pioderma gangrenoso: um desafio para o reumatologista
}

\author{
Luciano Ferreira Coelho ${ }^{1}$, Francine Guilherme Correia ${ }^{1}$, Fernanda Assis Ottoni², \\ Flávia Patrícia Sena Teixeira Santos ${ }^{3}$, Luciana Baptista Pereira ${ }^{4}$, Cristina Costa Duarte Lanna ${ }^{5}$
}

\begin{abstract}
RESUMO
O pioderma gangrenoso (PG) faz parte do espectro das dermatoses neutrofílicas, processos que têm em comum um padrão histológico similar, formado por infiltrado de leucócitos polimorfonucleares, de caráter não infeccioso e não neoplásico e sem vasculite primária. Caracteriza-se por úlceras dolorosas, com bordas imprecisas, de variados tamanhos e profundidade, localizadas principalmente nos membros inferiores, mas outras partes da pele, mucosas e outros órgãos podem estar envolvidos. A doença tem grande morbidade e seu curso pode ser crônico ou recidivante. A patogênese não é bem conhecida. Em 50 a 70\% dos pacientes, está associado a uma doença de base, como doença inflamatória intestinal, doenças reumáticas, hematológicas ou malignidades; pode apresentar-se de forma isolada. São analisados dois pacientes com o diagnóstico de pioderma gangrenoso e artrite associada, para ressaltar a importância do conhecimento dessa dermatose pelo reumatologista, já que o acometimento articular ocorre em cerca de $37 \%$ dos pacientes que apresentam essa síndrome neutrofílica.
\end{abstract}

Palavras-chave: pioderma gangrenoso, artrite, úlcera cutânea.

\section{INTRODUÇÃO}

O pioderma gangrenoso (PG) faz parte do espectro das dermatoses neutrofílicas, processos que têm em comum a infiltração por leucócitos polimorfonucleares na pele, no tecido subcutâneo e em outros órgãos, de caráter não infeccioso e sem vasculite primária. ${ }^{1}$

São apresentados dois pacientes com pioderma gangrenoso e artrite associada, acompanhados nos serviços de Reumatologia e Dermatologia do Hospital das Clínicas da UFMG.

\section{RELATO DE CASO}

Caso 1: LSG, sexo masculino, tem 16 anos de idade. Em outubro de 2001 , iniciou quadro de febre diária de até $40^{\circ} \mathrm{C}$, com aparecimento de nódulos subcutâneos, eritematosos e dolorosos em membros inferiores, artrite de cotovelos e tornozelos, sem rigidez matinal.

É acompanhado no Hospital das Clínicas da UFMG desde julho de 2002. Do mês seguinte até março de 2007, apresentou quatro recidivas, manifestando-se como nódulos eritematosos, vesículas que evoluíam para úlceras ou como lesões ulceradas pequenas desde o início. Os episódios foram tratados com curativos, corticoide oral e antibióticos. Em maio de 2007, surgiram, no membro inferior direito, novas úlceras dolorosas, profundas e bem maiores que as anteriores, que rapidamente coalesceram. Não houve outras manifestações. O diagnóstico de pioderma gangrenoso foi confirmado pela equipe de dermatologistas. $\mathrm{O}$ tratamento com prednisona $1 \mathrm{mg} / \mathrm{kg} / \mathrm{dia}$ foi iniciado com ótima resposta, seguindo-se redução gradual até sua suspensão em março de 2008, e introdução de metotrexato

Recebido em 22/07/2008. Aprovado, após revisão, em 18/01/2009. Declaramos a inexistência de conflitos de interesse.

Hospital das Clínicas da UFMG - Serviços de Reumatologia e Dermatologia.

1. Médico-Residente em Reumatologia, Hospital das Clínicas, UFMG

2. Médica Dermatologista, Membro Efetivo da Sociedade Brasileira de Dermatologia

3. Reumatologista Pediátrica, Mestre em Pediatria, Preceptora da Residência em Reumatologia, Hospital das Clínicas, UFMG

4. Professora Assistente de Dermatologia, Faculdade de Medicina da UFMG

5. Professora Adjunta, Doutora, Departamento do Aparelho Locomotor, Faculdade de Medicina, UFMG

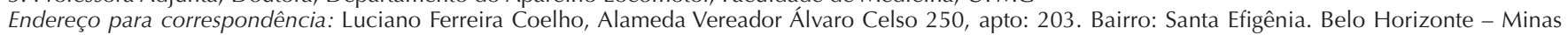

Gerais. CEP: 30150-260. e-mail: lucianofcoelho@terra.com.br 
$10 \mathrm{mg} / \mathrm{semana}$. Em junho de 2008, houve recorrência das lesões, com reajuste das medicações e boa resposta. Atualmente, o paciente está sem lesões cutâneas ou artrite.

Os exames relevantes são mostrados a seguir: (11/2001) Anemia normocrômica/normocítica; proteína $\mathrm{C}$ reativa: 69,5 $\mathrm{mg} / \mathrm{dL}$; hemossedimentação: $90 \mathrm{~mm} / \mathrm{h}$; fator antinuclear/fator reumatoide negativos; (04/2003) PPD: não reator; Rx tórax: normal; (08/2004) BAAR no escarro, em lóbulos de orelhas e cotovelos: negativo; eletroforese de proteínas: normal; sorologia hepatite B e C: negativa; (04/2003) biópsia do nódulo com infiltrado inflamatório composto de polimorfonucleares neutrófilos e eosinófilos na derme profunda e no subcutâneo, edema intersticial e congestão; (03/2006) eletroforese de hemoglobina: AA; ANCA, anticardiolipina/anticoagulante lúpico: negativos; (03/2007) biópsia de pele - derme edemaciada com infiltrado inflamatório linfo-histiocitário predominando nas áreas perivasculares e polimorfonucleares neutrófilos, atingindo a hipoderme. Sem sinais de neoplasia ou microorganismos específicos.

Caso 2: SSF, sexo feminino, tem 22 anos de idade e foi internada em $1^{\circ}$ de fevereiro de 2007 com febre, artralgias em joelhos e tornozelos e várias úlceras em membros inferiores, com um mês de evolução. À admissão, seu estado geral era regular: estava hipocorada, eupneica, emagrecida. Pressão arterial: 110 x $70 \mathrm{mmHg}, \mathrm{FC}: 110 \mathrm{bpm}$, ausculta cardíaca e pulmonar normais e baço palpável a $2 \mathrm{~cm}$ do rebordo costal esquerdo. Havia úlceras disseminadas em membros inferiores, com fundo necrótico e algumas com secreção purulenta, com bordas elevadas e irregulares e hiperemia. Sem artrites. Três anos antes apresentara quadro semelhante, porém mais leve, que foi tratado com prednisona e dapsona, que evoluiu satisfatoriamente. Não havia manifestações clínicas específicas de doenças autoimunes

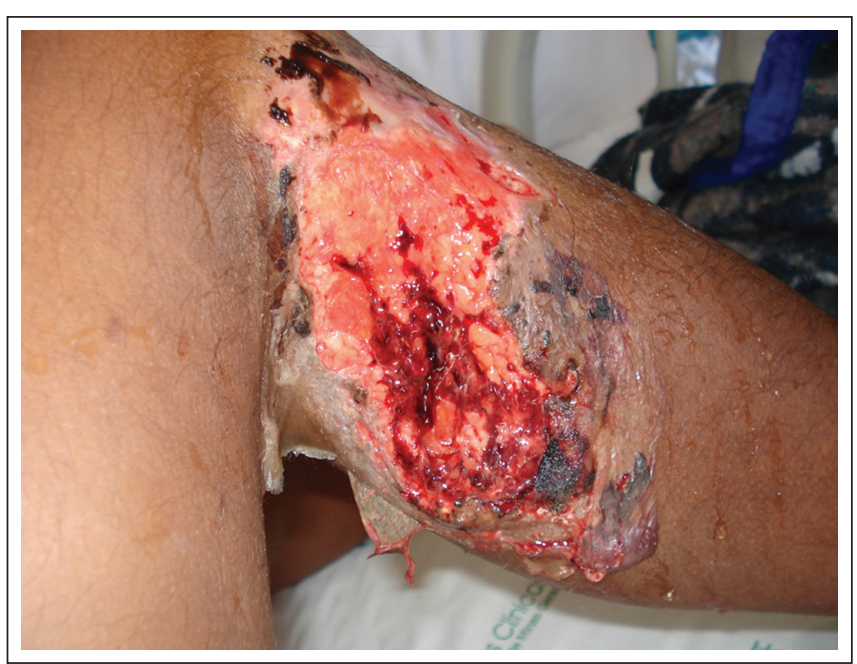

Figura 1. Lesão ulcerada em paciente do caso 1. ou de doença inflamatória intestinal. A febre persistiu, apesar do uso de vários esquemas de antibióticos. Exames relevantes são mostrados a seguir: fator reumatoide, anticoagulante lúpico e anticardiolipinas, ANCA e crioglobulinas: negativos; FAN + 1/1280 (pontilhado fino, fracionamento negativo); Rx de mãos/ punhos: normal; ecocardiograma transtorácico normal; TC de abdome: imagens hipodensas e aumento do baço; sorologias para hepatites B, C e HIV: negativas; cultura do aspirado de coleção do baço: negativa; mielograma e biópsia de medula óssea: normais. Biópsia de pele: leve infiltrado inflamatório linfo-histiocitário, com alguns neutrófilos e plasmócitos nas áreas perivasculares na derme e denso infiltrado inflamatório linfo-histiocitário e grande número de polimorfonucleares na hipoderme. A pesquisa de fungos e bactérias foi negativa.

Iniciado tratamento para $\mathrm{PG}$ primário, com prednisona $60 \mathrm{mg} / \mathrm{dia}$ e ciclosporina $150 \mathrm{mg} / \mathrm{dia}$, com desaparecimento total das lesões e melhora dos sintomas sistêmicos. A dose de prednisona foi gradativamente reduzida até a suspensão; e a ciclosporina, mantida em $200 \mathrm{mg} / \mathrm{dia}$. Os exames de imagem mostraram redução no volume das imagens do baço. Atualmente está assintomática.

\section{DISCUSSÃO}

No primeiro paciente, o caráter recidivante e episódico do quadro cutâneo e articular, além das úlceras pouco típicas, exigiu um tempo longo de acompanhamento e extensa propedêutica, até a confirmação clínica do diagnóstico de PG. Não houve critérios para diagnóstico de uma doença articular inflamatória associada durante os anos de acompanhamento. A opção pelo metotrexato deveu-se à impossibilidade de a família

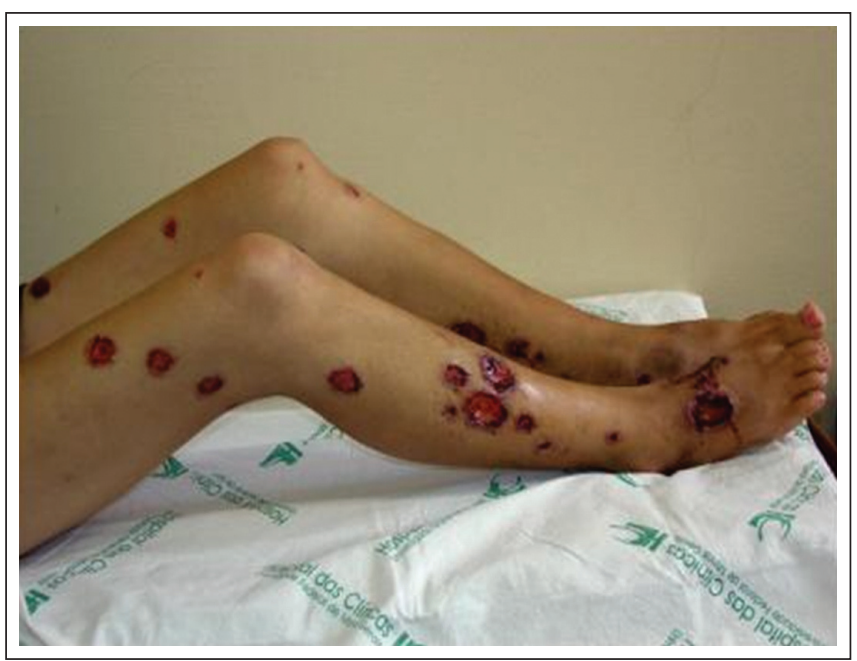

Figura 2. Lesões ulceradas em membros inferiores, paciente do caso 2. 
adquirir a ciclosporina e à necessidade de acompanhamento mais rigoroso. A paciente apresentada como caso 2, além de um quadro mais crônico de úlceras e artrite, apresentou lesões no baço, que motivaram propedêutica específica para excluir infecção e neoplasia. A melhora com o tratamento imunossupressor confirmou tratar-se de uma manifestação extracutânea do pioderma.

O PG é uma doença ulcerativa dolorosa, que cursa com exacerbações e remissões e pode evoluir com comprometimento articular. O pico de incidência está entre 20 e 50 anos, sendo as mulheres as mais afetadas. Os casos em crianças e adolescentes atingem $4 \%$ do total, e a incidência geral está estimada entre 3 e 10 casos/milhão de habitantes/ano. ${ }^{2}$

Em 50 a $70 \%$ dos pacientes, associa-se a uma doença de base, como doença inflamatória intestinal, doença reumática, hematológica ou malignidade. ${ }^{1}$ É descrita ainda associação com a síndrome PAPA (Pyogenic arthritis, pyoderma gangrenosum and acne). ${ }^{3}$

A patogênese é pouco compreendida, podendo existir uma disfunção em neutrófilos com oscilações metabólicas e trânsito anormal de neutrófilos. ${ }^{4}$ Nenhum defeito imunológico comum a todos os casos foi descrito. ${ }^{5}$

No início, surgem nódulos ou pústulas estéreis, dolorosas, que evoluem com ulceração central. Aúlcera clássica é extensa, tem bordas infiltradas, eritêmato-violáceas, subminadas, com fundo necrótico e com tecido de granulação. São profundas e atingem a derme e o tecido subcutâneo. As úlceras podem ser solitárias ou múltiplas, encontradas em qualquer parte do corpo, mais frequentemente em membros inferiores. Em cerca de $30 \%$ dos pacientes há história de trauma prévio desencadeando a lesão (patergia). Raramente podem ocorrer formas vegetantes ou bolhosas. ${ }^{2,5}$

Alguns pacientes apresentam febre, mal-estar e mialgias. Infiltrados neutrofílicos estéreis podem ser encontrados em outros órgãos. ${ }^{1,2} \mathrm{~A}$ artrite, presente em $37 \%$ dos casos, tem padrão variável: reumatoide clássico, assimétrica de membros inferiores e monoartrite de grandes articulações já foram descritos. ${ }^{3,6}$

Indicam-se culturas de secreções, estudo histológico para exclusão de malignidades, vasculites e infecções por fungos, microbactérias ou parasitas $\mathrm{O}$ estudo histopatológico nem sempre é conclusivo para o diagnóstico, pois as alterações podem ser inespecíficas e variam conforme o estágio da lesão. A infiltração por células inflamatórias da parede de vasos menores pode ocorrer, e a vasculite sistêmica deverá ser afastada. Se granulomas estiverem presentes, afastar doenças infecciosas. Os achados histológicos típicos incluem inflamação neutrofílica supurativa na epiderme e derme com necrose tecidual, reação vascular com infiltrado linfocítico perivascular, usualmente sem necrose vascular fibrinóide concomitante. ${ }^{5,7}$

Os critérios para o diagnóstico do PG incluem critérios maiores e menores, sendo a presença da ulceração, com eliminação de outras causas possíveis, fatores essenciais. ${ }^{4}$

$\mathrm{Na}$ doença disseminada ou de curso rápido e sem outra doença de base, as primeiras opções terapêuticas são o corticoide, a ciclosporina associada ou não à prednisona e a pulsoterapia venosa com metilprednisolona. Outros imunossupressores são relatados em caso de insucesso e úlceras refratárias não são incomuns. A analgesia potente e permanente é importante. ${ }^{5}$ A terapia cirúrgica terá como objetivo apenas a remoção de material necrótico pela possibilidade de patergia, com piora das lesões. ${ }^{8}$

\section{CONCLUSÃO}

O PG apresenta-se como um dos desafios no diagnóstico diferencial das doenças com queixas musculoesqueléticas. $\mathrm{O}$ conhecimento da apresentação clínica, do diagnóstico e do diagnóstico diferencial dessa doença em muito pode auxiliar o reumatologista na organização de seu raciocínio clínico e na forma de tratamento adotado. 


\section{REFERÊNCIAS}

\section{REFERENCES}

1. Callen JP. Pyoderma gangrenosum. Lancet 1998;351(9102):581-5.

2. Wollina U. Pyoderma gangrenosum - a review. Orphanet J Rare Dis 2007;2:19.

3. Levin J, Werth VP. Skin disorders with arthritis. Best Pract Res Clin Rheumatol 2004;20(4):809-26.

4. Su WPD, Davis MDP, Roger HW, Powell FC, Perry HO. Pyoderma gangrenosum: clinicopathologic correlation and proposed diagnostic criteria. Intern J Dermatol 2004;43(11):790-800.

5. Blitz NM, Rudikoff D. Pyoderma gangrenosum. Mt Sinai J Med 2001;68(4\&5):287-97.

6. Charles CA, Tracy LB, Falabella AF, Eaglstein WH, Kerdel FA, Kirsner RS. Poor prognosis of Arthritis-associated Pyoderma Gangrenosum. Arch Dermatol 2004;140(7):861-4.

7. Crowson AN, Mihm MC Jr, Magro C. Pyoderma gangrenosum: a review. J Cutan Pathol 2003;30(2):97-07.

8. Reichrath J, Bens G, Bonowitz A, Tilgen W. Treatment recommendations for Pyoderma gangrenosum: An evidence based review of the literature based on more than 350 patients. J Am Acad Dermatol 2005;53(2):273-83. 